\title{
The Learning Situation and Support Service System of Online Education: The Case Study of X University
}

\author{
Yanqing Yang1, Min Chen ${ }^{2}$, Xueqing Zeng², Liang $\mathrm{Yu}^{2}$ \\ ${ }^{1}$ Online and Continuing Education College, Southwest University, Chongqing, China \\ ${ }^{2}$ College of Computer and Information Science, Southwest University, Chongqing, China \\ Email: yangyq@swu.edu.cn
}

Received 21 April 2015; accepted 23 June 2015; published 26 June 2015

Copyright (C) 2015 by authors and Scientific Research Publishing Inc.

This work is licensed under the Creative Commons Attribution International License (CC BY). http://creativecommons.org/licenses/by/4.0/

(c) (i) Open Access

\begin{abstract}
With the development of information technology, the new generation of distance education "online education", which is developed with the support of multimedia computer technology and network technology, is attracting increasing attention around the world. This article summaries the status quo of online education of $X$ University that is the vanguard of China's online education, and conducts a survey about learning support service system of online education which will be meaningful to further optimization of online education in X University and provide references for online education of other universities.
\end{abstract}

\section{Keywords}

Online Education, Learning Situation, Support Service

\section{Introduction}

The development of network technology makes online education rapidly promoted and recognized in the country, and online education changes the traditional mode of education to some degree. Online education is a means of education, a way of learning and an idea as well as a form of teaching organization, which overcomes the lack of traditional distance education with the core of broadcast television technology, breaking the restrictions of time and space, and forms a "anytime, anywhere, interactive" teaching method, so we can expect that online education is not only the effective way to achieve leap-forward development of China's education, but also the main factor promoting a new round of Education Reform - the educational information around the word (Chen, Huang, \& Lu, 2010). At present, China's online education achieves the breakthrough in amount and the qualita- 
tive leap, making remarkable achievements. But it is easy to find that the online education in universities still have some problems in the construction of the school system, teaching staff, management innovation, teaching quality monitoring, etc. Therefore, we have to fully grasp the learning situation of online education, study learning support service system deeply, and continuously improve the level of teaching management of online education, improving the quality of personnel training in the online education. This investigation is carried out under such a background.

\section{Meaning of Online Education}

Online education is the form of teaching organization using modern information network tool whose equal center network environment is easy to communicate across time and space, interactive and having the openness of sharing information, which can develop the personality of students, achieving the concept of thinking students as the center finally. China's famous education technology expert, Mr. Nan Guonong, gives the definition of the online education that "online education is the learner-centered non-face education which which mainly combines with multimedia network." (Nan, 2002) Online education is a teaching activities which is based on network technology by using of the network environment (Zhang, 2002).

\section{Situation of Online Education College in X University}

Liu Dan, Sun Qiang in the "Status and Problems of online education Analysis" discussed China's online education, they said, "Although online education in our country started relatively late, from the beginning of the 1990s, but it presents a booming trend, after years of efforts, has made some achievements (Chen, Huang, \& Lu, 2010)". As the forefront of online education platform, the development of online education in Colleges and universities has become increasingly mature. According to the statistics, by the end of 2012, the students in our modern distance education pilot of online education in universities (Referred to as Online Education) have reached the sum of 37,850,000. The amount of students in reading is 5,700,000 in 2012. From the number of students, the online education is full of vitality, and huge market of students is enough to support the normal operation of online education institutions, so the prospect is optimistic.

Although China's reform and opening up policy economy have been a great development, funds of investing in education are still relatively short. With the continuous development of science technology, computer prices is dropping lower and lower, but according to China's economic condition, the computer still cannot obtain the comprehensive popularization. At the same time, teachers cannot get the training of online teaching technology system, and in the use of technology, they will give up the use of technology to the traditional familiar teaching methods when encountered difficulties and setbacks. Facing with the rapid rise of online education, the public and educators in China is lack of preparation in mind. And their computer skill level is not high, so using network is at a loss. In addition, Webpage quality is difficult to be assured, online learning management mechanism is terrible, online teaching service quality is not high, and online course evaluation is obsolete, lack of innovation, which cannot effectively meet the demand of the teaching.

From the view of phenomena, it is easy to blame the contradiction of size and quality, then they think that to control the scale can improve the quality; but in essence, it is necessary to bound to the process of teaching and learning. Teaching and learning is the main link in personnel training and the key to determining the quality of the personnel training. Teaching management is the guarantee of the organization and system that implement the teaching and learning process and the observation point of the level of online education personnel training (Chen \& Chen, 2010). Therefore, grasping the current situation of online education in university and finding the innovation nodes of education management mechanism plays a positive role in promoting the rapid development of online education in our university.

\section{Purpose and Method of Study}

\subsection{Objective}

Based on the above understanding of the status of online teaching, this research devoted to learning the actual operation situation of support service system at the learning center after school in online education college of our university, investigating and analyzing the evaluations and requirements of all kinds of learning support service to network learners, and revealing the main problems existing in the learning support service now. Then it 
provides reference for the feasibility building high efficient university network distance education learning support service system (Wang \& Ma, 2006).

\subsection{Method}

The objects in this research are students of distance education of online college in X University. And the survey is taken by random sampling method. We send 1500 questionnaires to teachers, students, civil servants, clerk, accountant, free occupation as well as each social stratum population. There are 1500 recoverable questionnaires, 1490 effective questionnaires, and the questionnaire recovery rate is $100 \%$, the effective questionnaire rate is 99.3\%. In the survey, there are 754 boys, accounting for 50.6\%, 736 girls, accounting for 49.4\%; 1298 young people from 20 to 40 years old, accounting for $87.1 \%$ of the total number; 600 people from high school to college, accounting for $40.3 \%, 890$ people from college to university, accounting for $59.7 \%$.

\section{Result and Analysis}

Online education is a new form of education, which transforms the most outstanding educational resources to the areas of lacking educational resources mostly with modern methods, providing learning opportunities and conditions for more people (Yan, Liu, Ren, Zhang, \& Li, 2005). How to ensure the learning effect and teaching quality of distance learning students in the online education and help students overcome all the difficulties and complete their education successfully is a problem that should not be ignored by university online education managers. In order to solve this problem effectively, we must establish the learning support service system. As one of the most central aspects of online education teaching process, learning support service system is an important factor related to the success or failure of online education. For the students who are separated from teachers, learning support service system is an important guarantee for the completion of their studies smoothly; for the online education itself, learning support service system is the platform to optimize teaching resources and the bridge to distance communication between teachers and student. After many years of development, online education learning support service system in our university has been continuously improved, but after the comprehensive survey, we find that at this stage, there are still some following problems in online education learning support service system

\subsection{Learning Resources Support Services}

Online education learning resources are mainly composed of Web courseware, video courseware, textbooks, digital library, learning CD-ROM and other elements. In the discovery of investigation, there are some problems with varying degrees of this element. In the survey, 944 people raised that the operation guidance and answers to exercises need to bet improved, accounting for $63.4 \%$; 266 people have put forward improving the content and form of learning resources, accounting for $17.9 \%$; in addition, there are 279 people making suggestions for improvement about chapters on practice, students excellent job, site navigation and other aspects, accounting for $18.7 \%$. Table 1 and Table 2 are the result of the survey on various teaching resources.

The main problem of Web courseware: 1) single learning content and the lack of interest; 2) the example and exercise is too little, the explanation on the network are not detailed enough and the pertinence is not strong; 3 ) the redundancy of courseware content and the lack of focus; 4) web courseware content update lag, affecting the normal learning process; 5) The font of the course is too small, the layout is not human enough.

\begin{tabular}{lcccccc}
\hline \multicolumn{7}{l}{ Table 1. Evaluation of teaching reasources. } \\
\hline Evaluation of project & Larger & Large & General & Small & Smaller & Scoring rate \\
\cline { 2 - 7 } & 498 & 354 & 215 & 20 & 8 & $97.44 \%$ \\
\hline $\begin{array}{c}\text { Supplementary materials for } \\
\text { learning help }\end{array}$ & 284 & 395 & 305 & 55 & 56 & $89.86 \%$ \\
$\begin{array}{c}\text { teaching CD for learning help } \\
\text { Review, self-testing exercises } \\
\text { for learning help }\end{array}$ & 1095 & 0 & 0 & 0 & 0 & $100 \%$ \\
\hline
\end{tabular}


Table 2. Evaluation of the network courseware.

\begin{tabular}{ccccccc}
\hline & \multicolumn{5}{c}{ Table column head } \\
Evaluation of project & Very satisfied & The basic satisfaction & Satisfied & Dissatisfied & Very dissatisfied & Satisfaction \\
\cline { 2 - 7 } & 448 & 323 & 682 & 33 & 4 & $97.52 \%$ \\
\hline $\begin{array}{c}\text { Network courseware } \\
\text { navigation satisfaction }\end{array}$ & 497 & 271 & 712 & 7 & 3 & $99.33 \%$ \\
$\begin{array}{c}\text { Network courseware } \\
\text { interface satisfaction }\end{array}$ & 429 & 318 & 698 & 40 & 5 & $96.98 \%$ \\
$\begin{array}{c}\text { Network courseware } \\
\text { content satisfaction }\end{array}$ & 390 & 344 & 708 & 39 & 9 & $96.78 \%$ \\
$\begin{array}{c}\text { Course content explain } \\
\text { satisfaction }\end{array}$ & & & & & 9 \\
\hline
\end{tabular}

The main problem of video courseware: 1) the video to explain the lesson is too little, the content update slow and not synchronized with the course; 2) the video courseware have to watch online, download speed is slow; 3 ) the video courseware stock is too little and making is rough; 4) the video courseware form is single, teaching methods of part of teachers is inflexible, and less attraction to students, which need further improvement; 5) the video courseware lack the function to solve the practical problems.

The main problem of textbooks: 1) the printing quality of part of textbook is low and version is stale; 2) the teaching materials and courseware content is not consistent; 3 ) the time that the teaching materials can be sent to students is late, and influence students' review of exam; 4) the utility is poor; 5) lack of various practice and analysis of classification.

The main problem of learning discs: 1) the quality of the practice learning CD-ROM disc has problems, and the video broadcast is not smooth; 2) the video format is not universal, some students cannot play the CD; 3 ) learning and teaching materials are not synchronized; 4) the number of the disk class are few, the teaching content is not complete; 5) the teaching level of the part of the teachers remains to be further improved.

The main problem of the digital library is that the steps to visiting are too many and the procedure is too cumbersome.

Web courseware is the most basic learning resources, which learners use to carry out independent learning. The construction of multimedia network courseware must be standard, professional, famous and commercial (Wang \& Xiang, 2004). Multimedia network courseware must be made by professional production staff and professional teachers who make full use of hypermedia technology and streaming video technology to product together according to the characteristics of the course, and it should hire the best teachers of this discipline. The standard structure mode of the multimedia network courseware should be made by the professional company to develop according to the characteristics of online education. Relying on the making of the elite teachers, multimedia network courseware, which is scientific, advanced and have professional standards, guarantee the "classroom teaching" quality in online education and the optimization of the electronic teaching plan.

\subsection{The Process of Learning Support Services}

The online education is different from the full-time higher education of which the teaching ways mainly are the network media. It lacks the face-to-face communication. There are 1500 participants in the survey in all. 1206 people of them said that they would solve the problems happening in the daily work and learning by the Internet. Network learning process mainly includes: coursework, online communication, consultation and Q \& A, counseling courses, review and examination guidance, thesis guidance, satellite and network broadcast, face-to-face communication and so on. The survey found that there are some problems in these following areas. Tables 3-5 are the result of the survey on the online learning process involving all elements.

The problem of homework: 1) the amount of homework is too much, unfocused; 2) the correct analysis for the course assignments are not timely; 3 ) the instructor's approval of coursework is not timely and attitude is not rigorous enough; 4) the contradiction between work and study of students is prominent, and the phenomenon of doing not hand in homework and handing in homework late is more prominent; 5) the innovation and the practicality in the coursework is not enough; 6) the communication between teachers and students is not enough.

Online consultation communication and Q \& A. In the process of online education, teachers and students have 
Table 3. Needs assessment of the process of online learning.

\begin{tabular}{|c|c|c|c|c|c|c|}
\hline \multirow{2}{*}{ Evaluation of project } & \multicolumn{6}{|c|}{ Table column head } \\
\hline & Really need & Need & Urgent need & Unwanted & Less & scoring rate \\
\hline To guide the learning time & 423 & 357 & 213 & 41 & 61 & $90.68 \%$ \\
\hline $\begin{array}{l}\text { To guide the curriculum } \\
\text { learning methods }\end{array}$ & 452 & 365 & 230 & 19 & 29 & $95.62 \%$ \\
\hline $\begin{array}{l}\text { To guide the content of } \\
\text { optional courses }\end{array}$ & 429 & 406 & 167 & 34 & 59 & $91.51 \%$ \\
\hline To guide the learning plan & 401 & 424 & 162 & 42 & 66 & $90.41 \%$ \\
\hline $\begin{array}{c}\text { To guide the face to face } \\
\text { course }\end{array}$ & 294 & 377 & 229 & 77 & 118 & $82.19 \%$ \\
\hline To guide the graduation thesis & 429 & 254 & 363 & 25 & 24 & $95.53 \%$ \\
\hline $\begin{array}{l}\text { To guide the learning } \\
\text { psychology }\end{array}$ & 309 & 390 & 162 & 93 & 141 & $78.36 \%$ \\
\hline
\end{tabular}

Table 4. Evaluation of the network learning supporting tool.

\begin{tabular}{ccccccc}
\hline \multirow{2}{*}{ Evaluation of project } & \multicolumn{5}{c}{ Table column head } \\
\cline { 2 - 7 } & Larger & Large & General & Small & Smaller & Scoring rate \\
\hline $\begin{array}{c}\text { E-mail support function } \\
\text { The course forum support } \\
\text { function }\end{array}$ & 300 & 285 & 389 & 67 & 54 & $88.95 \%$ \\
$\begin{array}{c}\text { Voice Q \& A support function } \\
\text { help }\end{array}$ & 372 & 281 & 367 & 43 & 32 & $93.15 \%$ \\
QQ group support function & 294 & 261 & 390 & 67 & 60 & $88.40 \%$ \\
Letter to support function & 245 & 321 & 362 & 66 & 52 & $89.22 \%$ \\
\hline
\end{tabular}

Table 5. Evaluation of the form of teaching.

\begin{tabular}{|c|c|c|c|c|c|c|}
\hline \multirow{2}{*}{ Evaluation of project } & \multicolumn{6}{|c|}{ Table column head } \\
\hline & Larger & Large & General & Small & Smaller & Scoring rate \\
\hline $\begin{array}{l}\text { The necessity of going out to } \\
\text { visit and study }\end{array}$ & 283 & 313 & 379 & 57 & 63 & $89.04 \%$ \\
\hline $\begin{array}{l}\text { The necessity of social } \\
\text { investigation and report } \\
\text { writing }\end{array}$ & 372 & 257 & 371 & 50 & 45 & $91.32 \%$ \\
\hline $\begin{array}{l}\text { The necessity of study } \\
\text { deeply in the practice base }\end{array}$ & 305 & 408 & 272 & 61 & 49 & $89.95 \%$ \\
\hline
\end{tabular}

the online consultation communication and Q \& A mainly by BBS, Email and other network instant communication tools. In this respect, the following problems mainly exist: 1) the classification of the forum is unclear, the page is not compact, network navigation is not strong, and part of the learning questions lack pertinence; 2) the communication platform is too single, and the interaction between teachers and students is not enough; 3) the online Q \& A period is too long, and the Q \& A is not timely, not careful, it can ineffectively solve the problems of students; 4) the network speed and symbol input problems need to be solved; 5) the learning statistical functions need to be further improved; 6) the examination registration lack the relevant information, and the content is relatively single.

The problem of curriculum guidance, review and examination guidance: 1) course review counseling update slow, and the analysis is too simple; 2) the review material resources is too little, unfocused, lacking exam simulation test and self-test exam; 3) the communication between professional course teachers and students is not 
enough; 4) the upload of the subjects of review outline and review simulation exam and other related information is not timely, affecting candidates preparing for the exam.

The problems of thesis guidance: 1) The creative quantity of science and technology thesis is not enough; 2) the graduation thesis guidance is not enough, the correction that guidance teachers make for students' thesis is not timely, and the communication is not enough; 3 ) students lack the understanding of the necessary steps for the paper and links, and the thesis progress is not unified; 4) the thesis writing time is too tight, and it is hard to write fine articles for students.

The main problem of satellite and network broadcast is that the cycle of live video course is too long, the time is too short, and the content is too little, lacking replay link, so it is necessary to upload live video course and made a CD-ROM for students to watch at any time. In the survey, there are 1420 people think that live video course is necessary, accounting for $94.7 \%$, and there are 625 people hope that the live video course will be arranged in a weekend day, accounting for $41.67 \%$, besides there are 467 people who are more willing to arrange the course from Monday to Friday night, accounting for $31.18 \%$.

The main problems of face-to-face course is that the opportunities are few, then there is the lack of face-toface communication between teachers and students, but we can arrange some professional guidance teachers to take the lecture tour at each teaching point, or have face-to-face training according to some important course to solve the problems in the study of students in the distance.

\subsection{Learning Management Support Services}

Learning management system includes daily teaching, educational administration work, students course examination and assessment, financial management and so on. In addition, the operation of the system have hardware support, software resources and technical support, people in operation must have the sense of service, and the people using system also have the initiative, which means that the operation of the system need to strengthen the management. The survey found that the learning management system also has the following problems (Table 6).

The problems of teaching: 1) the content of teaching is too simple, and the students cannot effectively learn theoretical knowledge; 2) the lack of the combination between theoretical research and practical operation in the process of teaching; 3 ) the learning time is tight, the learning task is heavy, and students don't have enough time to digest the knowledge; 4) the textbooks and other teaching equipment are not in place in time, influencing the effect of students' learning and progress; 5) There is little content about actual cases, analysis of problems and the methods of solving the problem in the process of teaching; 6) the choice of course lack pertinence.

The problems of educational administration work: 1) the work at the teaching station is not in place, and the notification of important information is not comprehensive and not timely, resulting in some students miss some important information; 2) the knowledge of degree application is deficient; 3) the result announcement of students examination and assessment is not timely; 4) the diploma issue slow.

The problems of students course examination and assessment: 1) the notification of examination information is not timely; 2) the amount of the part of the examination is too much, and the time of the exams is too short, which is not enough; 3 ) the time is too short to learn the part of the course, and the examination is just a form.

The problems of financial management: 1) tuition and textbook fees are so high that some students cannot afford; 2) the fees are not standardized, lacking expenses lists and the corresponding receipts; 3 ) there are a larger number of centralized delivery fees each year that some students cannot afford.

\subsection{Learning Center Support Services}

Our online education learning center mainly includes the following tasks: one is the teaching assistant work, the

Table 6. Evaluation of teaching management.

\begin{tabular}{ccccccc}
\hline \multirow{2}{*}{ Evaluation of project } & Larger & Large & General & Small & Smaller & Scoring rate \\
\cline { 2 - 7 } & 676 & 373 & 388 & 33 & 20 & $96.44 \%$ \\
\hline $\begin{array}{c}\text { The school education for } \\
\text { learning help }\end{array}$ & 671 & 365 & 415 & 33 & 6 & $97.38 \%$ \\
$\begin{array}{c}\text { The learning statistical } \\
\text { functions for learning help }\end{array}$ & & & & & & \\
\hline
\end{tabular}


second is the organization and management, the third is to improve the learning environment. At present, our online education learning center has been relatively perfect, but we still find some problems in the survey.

The problems ofthe teaching assistant work is that lacking communication and interaction, the delivery of some important notice is not timely and complete, etc.

The problems of the organization and management: 1) the lack of contact between the centers; 2) the relevant staff in the branch center know too little about the teaching work; 3) the responsibility of the learning center teachers is not strong, the staff is not careful and patient, and their attitude is not correct.

The problem of learning environment is that the professional field is narrow and the number of teaching points is relatively less.

The establishment of learning centers plays the role of coordination and information communication, and its role of organization cannot be ignored. Learning center is a significant guarantee of delivering teaching contents and realizing the process of distance teaching, an important means which modern distance education experimental colleges use to enhance the efficiency of management and strengthen the support services towards students, and a vital way of promoting the interpersonal communication between teachers and students, and between students and students, and constructing the environment of imparting knowledge and educating people (Qin, 2004). Learning center and its counseling teachers need to pay more attention to communication with students and the organization of teaching and activities, which can reinforce learning, increase communication opportunities, and be better to urge the students learning.

\section{Conclusion}

The famous scientist Xuesen Qian discussed about the future education. He said that "the future of education = human brain + computer + internet". This will be the online education (Yang, 2014).

In order to solve the current problems in education, the following strategies were proposed: 1) To strengthen infrastructure construction, adjusting the structure of colleges and universities' online education resources; 2) To further improve the quality management and quality assessment system; 3) To Realize educational resources to actively use the university network diversification (Zheng \& Li, 2013).

We found that teaching management was the weakest link in our online education, which was the crux problem of affecting the reputation of the online education, and was too urgent to improve. Online education teaching management must be based on network location and we should have a clear understanding of the law. We can summary the initial results and experiences comprehensively and objectively, and then generalize the online education law seriously with China's national conditions. And we also should have the deep reflection of lessons and problems in the practice. What's more, we can take a thorough study on the related problems, analyze the causes, and explore the way to solve for our online education actively, hoping that we can make new and greater contributions for the career of our online education.

\section{Acknowledgements}

This work was supported by the Humanity and Social Science Research Youth foundation of Southwest University under Grant No. SWU08111, the Fundamental Research Funds for the Central Universities under Grant No. XDJK2014A002, and the Doctoral Fund of Southwest University under Grant No. SWU1110361.

\section{References}

Chen, L., \& Chen, G. (2010). Survey and Analysis of Pilot Higher Education Teaching Management Network. Distance Education in China, 1, 21-26.

Chen, X. Y, Huang, Y. M, \& Lu, T. (2010). Summary of the Current Status and the Development Trend of the Network Education. http://www.doc88.com/p-49528556650.html

Nan, G. N. (2002). IT Education in Creative Talents. Audio-Visual Education Research, 1, 42-45.

Qin, L. (2004). Current Situation and Countermeasures for College Network Education. Master's Thesis, Linfen: Shanxi Normal University.

Wang, C. L, \& Ma, X. F. (2006). Investigation and Analysis on the Current Situation of Learning Support Service. Chinese Audio-Visional Educational, 7, 31-34.

Wang, S. C, \& Xiang, C. Y. (2004). Talk Network Education in Building Digital Learning Resources. China Adult Educa- 
tion, 8, 25-26.

Yan, Q. L, Liu, R. X, Ren, Y. L, Zhang, L. J., \& Li, Y. D. (2005). Establishment and Improvement of the Open Distance Learning Support Service System. Journal of Career Academy, 1, 58-61.

Yang, Y. X. (2014). Current Status and Outlook of Network Education. Industrial \& Science Tribune, 13, 153-154.

Zhang, J. (2002). New Ideas in Education Online Education. Audio-Visual Education Research, 5, 29-32.

Zheng, Y. Y, \& Li, X. N. (2013). Current Situation of High Education and Countermeasures. Testing and Evaluation, 8, $94-$ 96. 